\title{
O Pacto Nacional pela Alfabetização na Idade Certa em ação: revisão de literatura*
}

\author{
Marcia Aparecida Alferes ${ }^{a}$ \\ Jefferson Mainardes ${ }^{b}$
}

\section{Resumo}

O artigo apresenta uma revisão de literatura sobre o Pacto Nacional pela Alfabetização na Idade Certa (PNAIC), abrangendo 64 trabalhos, do período de 2013 até 2016. As pesquisas apontaram o PNAIC como uma política abrangente que conjuga diversas ações, dentre as quais, a formação continuada de professores alfabetizadores. Concluiu-se que poucas pesquisas abordam o PNAIC, no contexto da sala de aula, e poucos trabalhos discutem o PNAIC enquanto política educacional. São apresentados alguns aspectos que necessitam ser aprofundados em pesquisas futuras.

Palavras-chave: PNAIC. Política Educacional. Formação continuada.

\section{Introdução}

Neste artigo, apresentamos uma análise de 64 trabalhos sobre o Pacto Nacional pela Alfabetização na Idade Certa (PNAIC), publicadas no período de 2013 a 2016. Tendo em vista o elevado número de pesquisas e publicações localizadas, optou-se por analisar apenas os trabalhos oriundos de pesquisa de campo ou análise documenta ${ }^{1}$. A importância do levantamento está relacionada à necessidade de compreender a política de alfabetização e de formação continuada de professores alfabetizadores, da forma mais ampla possível. Ball (2013, p. 9) explica que, normalmente, as políticas estão relacionadas a uma ideia de progresso ou mudança

\footnotetext{
* Financiamento da Coordenação de Aperfeiçoamento de Pessoal de Nível Superior (Capes).

a Universidade Estadual de Ponta Grossa, Ponta Grossa, PR, Brasil.

b Universidade Estadual de Ponta Grossa, Ponta Grossa, PR, Brasil.

1 O levantamento completo encontra-se disponível em: www.researchgate.net. O referido levantamento é atualizado de forma sistemática e permanente. Os trabalhos publicados a partir de 2017 serão analisados em publicações futuras.
}

Recebido em: 24 jan. 2017

Aceito em: 20 jul. 2018 
que se desenha "[...], a partir das insuficiências do presente para algum estado futuro de perfeição, onde tudo funciona e funciona bem, como deveria ser". Desse modo, é fundamental compreender o PNAIC, sem deixar de considerar que diversas políticas anteriores, voltadas a resolver os mesmos problemas já foram propostas e encerradas, sem que a questão central do problema tenha sido resolvida.

Essa revisão integra uma pesquisa mais ampla, que objetivou analisar a produção do PNAIC, enquanto política educacional (nível macro), bem como sua recontextualização da política nos níveis meso e micro, ou seja, na formação continuada de professores alfabetizadores e na prática pedagógica desses professores (ALFERES, 2017) ${ }^{2}$. A pesquisa fundamentou-se na teoria de Basil Bernstein sobre a estruturação do discurso pedagógico, processo de recontextualização e modelos pedagógicos de competência e desempenho e, também, na teoria da atuação (BALL; MAGUIRE; BRAUN, 2016). Uma das principais conclusões da pesquisa citada é que o PNAIC é um programa abrangente, necessário e relevante para a melhoria da qualidade da aprendizagem no ciclo de alfabetização. No entanto, constitui condição necessária, mas não suficiente para promover uma alteração significativa dessa qualidade, pois enfatiza a formação continuada e a disseminação de determinadas concepções e práticas, por meio de materiais específicos. Uma alteração mais significativa demanda investimentos em outros aspectos, tanto intra quanto extraescolares. Argumentou-se também que os princípios e propostas do PNAIC são recontextualizados nos contextos meso (Secretaria de Educação, Universidades, encontros de formação) e micro (sala de aula). Os orientadores de estudo e professores alfabetizadores interpretam, e traduzem em ação, os textos do PNAIC de formas diferenciadas. Ainda, com base em aspectos da teoria de Bernstein, argumenta-se que o PNAIC apresenta elementos da chamada pedagogia mista, ou seja, fundamenta-se no modelo pedagógico de competência e, também, em alguns aspectos do modelo pedagógico de desempenho. Por um lado, o Pacto enfatiza o emprego de práticas sistemáticas no processo de alfabetização e monitoramento da aprendizagem dos alunos (o que está relacionado ao modelo de competência). Por outro lado, há preocupação com a melhoria de índices e desenvolvimento de estratégias de avaliação externa (modelo pedagógico de desempenho).

O PNAIC foi criado em 2012, com o propósito de cumprir a meta 2 estabelecida pelo movimento Todos pela Educação: "toda criança plenamente alfabetizada até os 8 anos" (TODOS PELA EDUCAÇÃO, 2006). A meta 2 é o resultado de

\footnotetext{
2 Uma síntese dos resultados da referida pesquisa pode ser encontrada em Alferes e Mainardes (2018).
} 
uma agenda definida pelo setor privado, no âmbito do referido Movimento, e que foi incorporada pelo Governo Federal, principalmente na definição do Plano de Desenvolvimento da Educação (PDE) e do Plano de Metas Compromisso Todos pela Educação.

O PNAIC foi instituído pela Portaria $\mathrm{n}^{\circ} 867$, de 4 de julho de 2012, lançado em 8 de novembro de 2012, com o objetivo de criar estratégias para que, ao final do $3^{\circ}$ ano do Ensino Fundamental, todas as crianças estejam alfabetizadas (BRASIL, 2012). Para isso, o conceito de pacto surge como compromisso formal entre Ministério da Educação e as Secretarias Estaduais, Distrital e Municipais de educação, no intuito de reafirmar e ampliar o previsto no Plano de Metas Compromisso Todos pela Educação. Por se tratar de um programa abrangente e relevante, diversas pesquisas têm sido realizadas sobre o PNAIC. Neste artigo apresentamos uma síntese de algumas dessas produções.

\section{Metodologia}

A pesquisa da qual trata o presente artigo, classifica-se como uma revisão de literatura, cujo objetivo é sintetizar as conclusões de um conjunto de pesquisas sobre uma temática específica. A pesquisa envolveu a consulta no Banco de Teses e Dissertações da Coordenação de Aperfeiçoamento de Pessoal de Nível Superior (Capes), na Plataforma Sucupira, no Portal de Periódicos da Capes, na Scientific Electronic Library Online (SciELO) e em sites de eventos científicos. Os descritores utilizados foram: "Pacto Nacional pela Alfabetização na Idade Certa", "PNAIC", "alfabetização na idade certa" e "formação de professores alfabetizadores". Foram catalogados 144 textos, publicados no período de 2013 a 2016. Desse total, 64 foram classificados como textos oriundos de pesquisa de campo ou documental (Tabela 1), 23 como trabalhos publicados em anais de eventos científicos e 57 como relatos de experiência.

Tabela. Quantitativo de trabalhos que abordam sobre o PNAIC, conforme o tipo de material incluído na revisão de literatura (2013-2016).

\begin{tabular}{lc}
\hline Material & Quantidade \\
\hline Teses & 2 \\
Dissertações & 23 \\
Capítulos de livro & 8 \\
Artigos & 31 \\
Total & $\mathbf{6 4}$ \\
\hline
\end{tabular}

Fonte: Dados da pesquisa (2016). 
Nessa revisão, optou-se por analisar apenas os 64 textos decorrentes de pesquisa de campo ou documental, os quais foram classificados em sete categorias, definidas a partir da leitura integral dos textos (Quadro). Os demais trabalhos, classificados como relatos de experiência e trabalhos completos em anais de evento, não foram incluídos na revisão, mas constituem fonte de pesquisa para outros trabalhos que tenham, como objetivo, analisar os resultados do PNAIC.

A maioria dos textos incluídos nessa revisão (67\%) enquadra-se nas categorias PNAIC como Política Educacional e PNAIC e Formação de professores (43 textos). As categorias com menor número de trabalhos foram PNAIC e planejamento, ensino e aprendizagem no PNAIC (5\% e 1\%, respectivamente).

Quadro. Total de trabalhos incluídos na revisão de literatura (2013-2016), por categoria.

\begin{tabular}{|c|c|c|}
\hline Categoria & Autor(es)/ano & $\begin{array}{c}\text { Total } \\
(\%)\end{array}$ \\
\hline $\begin{array}{l}\text { PNAIC como } \\
\text { Política } \\
\text { Educacional }\end{array}$ & $\begin{array}{l}\text { Almeida (2014); Antunes, et al. (2014); Barros e Pereira } \\
\text { (2014); Boscolo e Campos (2014); Brito e Viédes (2015); } \\
\text { Cardoso e Cardoso (2016); Cardoso e Rodrigues (2014); } \\
\text { Cruz e Martiniak (2015); Fidelis et al. (2014); Klein et al. } \\
\text { (2016); Leite (2014); Lucachinski (2015); Lucachinski e } \\
\text { Tondin (2016); Manzano (2014); Mindiate (2015); Moreira } \\
\text { e Saito (2013); Porto (2016); Ribeiro e Albuquerque (2015); } \\
\text { Santos, N. (2015); Santos, P. (2015); Silva et al. (2014); } \\
\text { Souza e Costa (2015); Tedesco (2015); Ventura (2016); } \\
\text { Viédes (2015); Vieira (2015). }\end{array}$ & $26(41 \%)$ \\
\hline $\begin{array}{l}\text { PNAIC e Formação } \\
\text { de professores }\end{array}$ & $\begin{array}{l}\text { Ansiliero e Rosa (2014); Antunes et al. (2016); Cabral } \\
\text { (2015); Couto e Gonçalves (2016); Frambach e Vidal } \\
\text { (2015); Garcez (2015); Jesus (2015); Kaiuca (2015); } \\
\text { Martiniak e Cruz (2015); Moreira e Silva (2016); Pires e } \\
\text { Schneckenberg (2015); Salomão (2014); Santiago (2015); } \\
\text { Santos, C. (2015); Shimazaki e Menegassi (2016); Silva et } \\
\text { al. (2016); Souza (2014); Souza, T. (2015). }\end{array}$ & 17 (26\%) \\
\hline $\begin{array}{l}\text { Análise de } \\
\text { material do PNAIC }\end{array}$ & $\begin{array}{l}\text { Báfica et al. (2014); Klein (2015); Melo (2015); Monteiro } \\
\text { (2015); Resende (2015); Souza (2014); Souza, J. (2015). }\end{array}$ & $7(11 \%)$ \\
\hline PNAIC e avaliação & $\begin{array}{l}\text { Dickel (2016); Micarello (2015); Minatel et al. (2015); Rosa } \\
\text { (2014), Silva (2015). }\end{array}$ & $5(8 \%)$ \\
\hline PNAIC e currículo & $\begin{array}{l}\text { Axer (2014); Frangella (2016a; (2016b); Leal (2015); Toti } \\
\text { (2014). }\end{array}$ & $5(8 \%)$ \\
\hline $\begin{array}{l}\text { PNAIC e } \\
\text { planejamento }\end{array}$ & $\begin{array}{l}\text { Alcover (2016); Eleutério (2014); Jäger, Pereira e Nörnberg } \\
\text { (2014). }\end{array}$ & $3(5 \%)$ \\
\hline $\begin{array}{l}\text { Ensino e } \\
\text { aprendizagem no } \\
\text { PNAIC }\end{array}$ & Sá e Pessoa (2016). & $1(1 \%)$ \\
\hline Total & & $64(100 \%)$ \\
\hline
\end{tabular}

Fonte: Dados da pesquisa (2016) 


\section{PNAIC como Política Educacional}

Tal categoria inclui textos que tratam o PNAIC como uma política pública e que buscam analisar a sua atuação no contexto da prática ${ }^{3}$. Alguns textos abordam os seguintes aspectos: a utilização do material didático distribuído pelo Ministério da Educação, tanto no planejamento, como nas aulas dos professores alfabetizadores (ANTUNES et al., 2014; BARROS; PEREIRA, 2014; BOSCOLO; CAMPOS, 2014; CARDOSO; RODRIGUES, 2014); os recursos utilizados na formação de orientadores de estudo, como meio para melhorar a prática pedagógica e desenvolver, nos alunos, o gosto pela leitura (FIDELIS et al., 2014); o aprimoramento da atuação docente, com melhorias na organização das rotinas de trabalho, planejamentos, registros sobre a aprendizagem dos alunos, a avaliação, as atividades de leitura, a produção escrita e a exploração dos gêneros textuais, bem como a organização dos tempos e espaços da prática pedagógica (BOSCOLO; CAMPOS, 2014; KLEIN et al., 2016); os cadernos de memoriais de formação e as rodas de conversa, como instrumentos facilitadores para a formação de professores (VIEIRA, 2015); a segurança que o PNAIC proporcionou para trabalhar com alunos com dificuldades de aprendizagem (CARDOSO; CARDOSO, 2016); a relevância do PNAIC para o desenvolvimento pessoal e profissional dos professores em consonância com outro programa já implantado em um município (TEDESCO, 2015); o PNAIC como uma política abrangente (SANTOS, P., 2015), na qual as vozes daqueles que organizam e que colocam o Programa em ação emergem, revelando que, apesar dos desafios, houve fortalecimento dos laços profissionais por meio de trocas de experiências. Além disso, a formação de professores tornou-se um processo mais contínuo (ALMEIDA, 2014; VIEIRA, 2015) e as Universidades, mais atuantes e preocupadas com essa formação (SOUZA; COSTA, 2015).

A análise dos textos incluídos nessa categoria revelou que: a) os discursos presentes nos textos políticos do PNAIC são oriundos de demandas políticas (melhorar o índice de alfabetização demonstrado por avaliações em larga escala) e demandas sociais (diminuir o fracasso na alfabetização) (ALMEIDA, 2014; VENTURA, 2016); b) embora o PNAIC seja uma política descontínua, em virtude de mudanças no Governo federal e de instabilidade na alocação de recursos financeiros (SANTOS, P., 2015), é importante para capacitar os professores alfabetizadores para explorarem os recursos disponíveis na escola, por meio de situações lúdicas e priorizando a problematização da diversidade

\footnotetext{
3 A perspectiva teórica assumida na pesquisa de campo (ALFERES, 2017) baseava na teoria da atuação (theory policy enactment), formulada por Ball et al. (2016). A teoria da atuação rejeita a ideia de que as políticas são meramente implementadas. Os autores defendem que as políticas são interpretadas e traduzidas no contexto da prática. Os autores destacam a necessidade de analisar as dimensões contextuais nos quais as políticas são atuadas.
} 
cultural (MINDIATE, 2015); c) o PNAIC é um projeto nacional de formação de professores alfabetizadores, que conta com a participação de Instituições de Ensino Superior (IES) (PORTO, 2016); d) as políticas educacionais voltadas para alfabetização foram pensadas historicamente para atender, momentaneamente, as necessidades governamentais. Isto se traduziu em ações elaboradas, conforme a intencionalidade de cada governo, ou seja, ações isoladas, diferenciando-se de um projeto mais amplo (BRITO; VIÉDES, 2015; MOREIRA; SAITO, 2013); e e) as políticas educacionais vêm sendo implementadas com o objetivo de diminuir as desigualdades sociais através da educação, e isso inclui o PNAIC.

A formação continuada de professores, proporcionada pelo PNAIC, é apontada como uma das mais promissoras possibilidades de reverter os índices elevados de analfabetismo, baixo desempenho escolar e distorção idade-ano. No entanto, acredita-se que não é suficiente propor políticas educacionais objetivando a redução da desigualdade social, sem que as estruturas sociais, políticas e econômicas sejam reestruturadas para a construção de uma sociedade mais justa e igualitária (LUCACHINSKI, 2015; LUCACHINSKI; TONDIN, 2016). Ribeiro e Albuquerque (2015) consideram o PNAIC como uma política pública que poderá ter impacto, tanto nas práticas quanto nas concepções que o sustentam. As autoras consideram que no campo, muitas crianças podem iniciar seus estudos em idade mais avançada e que, devido ao trabalho lá exercido, a continuidade desses estudos pode ser interrompida.

Cardoso e Cardoso (2016) destacam dois aspectos relevantes: a) que professores alfabetizadores, orientadores de estudo, coordenadores locais e demais profissionais envolvidos no PNAIC exercem papel ativo na interpretação e reinterpretação dessa política pública e, consequentemente, seus modos de pensar influenciam, sobremaneira, no processo de implementação da política, e b) apesar dos indícios favoráveis, quanto à mudança da prática dos professores, não há como afirmar que tais ações implicarão o alcance do objetivo de alfabetizar todas as crianças. Silva et al. (2014) apresentam que, no contexto da prática ${ }^{4}$, nos dois municípios pesquisados, há diferenças na implantação do PNAIC. Para as autoras, o PNAIC é reinterpretado e recriado e produz efeitos e consequências que podem representar mudanças e transformações no programa original.

Uma crítica à implementação do PNAIC no estado de São Paulo é realizada por Manzano (2014), que afirma que o PNAIC é um programa educacional, cuja concepção de formação de professores alfabetizadores revela-se ultrapassada

\footnotetext{
4 Embora mencionem o contexto da prática, as autoras não realizaram observações em salas de aula. Suas conclusões estão embasadas em entrevistas realizadas com coordenadoras municipais, orientadoras de estudos e professoras alfabetizadoras de dois municípios.
} 
e autoritária. Para a autora, a implementação, no município de São Paulo, tem sido a expressão do modelo de Estado regulador, pois a formação de professores alfabetizadores caracteriza-se mais como reguladora de práticas do que promotora do desenvolvimento profissional docente.

Para Leite (2014), embora o PNAIC tenha ofertado aos seus participantes a reflexão sobre os processos de alfabetização e letramento, com material acessível e de excelente qualidade, ocorreram alguns entraves na implementação do Programa, tais como: a) atraso na entrega dos materiais; b) a não inserção dos diretores e coordenadores pedagógicos na formação; c) a pouca mobilização dos professores cursistas, entre outros.

Outra crítica ao PNAIC foi feita por Santos, N. (2015), que considerou que a organização para a realização da formação aposta na transposição homogeneizada das ações previstas nos cadernos de formação, não possibilitando alcançar as especificidades dos contextos locais. Ao impedir a participação dos coordenadores pedagógicos nas ações formativas do PNAIC, negligencia-se o fato de que, na educação municipal, são esses profissionais os responsáveis por coordenar as ações de formação continuada no âmbito das unidades escolares, bem como apoiar os professores alfabetizadores em suas práticas pedagógicas, e os alunos no processo de aprendizagem.

Viédes (2015) considera que, independente da política pública de alfabetização, são eles que estão na realidade local e são conhecedores das necessidades dos alunos do ciclo de alfabetização. Por isso, as políticas de governança que vão e vêm, cada qual querendo estampar a própria marca, não podem ser mais relevantes que o papel desses docentes.

Cruz e Martiniak (2015) destacam que a implementação do PNAIC esbarra em algumas dificuldades estruturais e relacionadas à prática pedagógica do professor. Uma delas é a concepção de alfabetização e a importância da formação continuada para o exercício da docência. As autoras consideram que o processo de alfabetização é complexo e multifacetado. Por isso, o exercício da docência requer que o professor tenha o domínio de conhecimentos teóricos sobre a alfabetização e seus determinantes.

\section{PNAIC e a formação de professores}

Na segunda categoria foram incluídos trabalhos que destacam a centralidade que a Política Educacional tem dado à figura do professor como responsável pela qualidade do ensino e, por isso, o investimento em formação continuada 
como forma de melhorar os índices de alfabetização revelados nas avaliações realizadas em larga escala (ANSILIERO; ROSA, 2014; CABRAL, 2015; MOREIRA; SILVA, 2016; PIRES; SCHNECKENBERG, 2015; SANTIAGO, 2015; SHIMAZAKI; MENEGASSI, 2016; SILVA et al., 2016; SOUZA, 2014; SOUZA, T., 2015). Outras pesquisas apontam os programas que antecederam o PNAIC, com destaque para seus marcos legais e históricos (ANSILIERO; ROSA, 2014; CABRAL, 2015; SALOMÃO, 2014, SOUZA, T., 2015). Cabral (2015) apresenta os aspectos que diferenciam o PNAIC de outros programas já implantados pelo Governo Federal. Silva et al. (2016) argumentam que as políticas de formação de alfabetizadores, no Brasil, são regidas por duas estratégias distintas e complementares, a saber: a ênfase na regulação dos desempenhos e a busca de perfis formativos inovadores. O PNAIC reitera a ênfase nos processos de avaliação de desempenhos (de alunos e professores).

Os aspectos positivos apontados nas pesquisas revelam que a formação continuada de professores do PNAIC contribuiu para: a) mudanças na postura dos orientadores de estudo, com relação ao encaminhamento do planejamento pedagógico, a permanência dos professores alfabetizadores em classes de alfabetização, o investimento em materiais didáticos e pedagógicos e o pagamento de bolsas para os professores participantes (MARTINIAK; CRUZ, 2015); b) o compartilhamento de experiências entre os participantes (FRAMBACH; VIDAL, 2015; KAIUCA, 2015), bem como uma avaliação contínua das práticas de alfabetização e preparação de atividades diversificadas, considerando a heterogeneidade dos alunos (ANTUNES et al., 2016); e c) que a formação constituísse um processo de aprendizagem continuada, no qual os diversos conhecimentos construídos consideraram as trajetórias profissionais advindas da formação inicial e da prática pedagógica (COUTO; GONÇALVES, 2016).

Garcez (2015) revelou a importância do PNAIC para a formação inicial de professores nos cursos de Pedagogia. Shimazaki e Menegassi (2016) destacaram as melhorias ocorridas além das práticas docentes dos orientadores de estudo: a) realização de trabalhos externos para formação continuada; b) participação em projetos de pesquisa institucional; c) apresentação e participação em eventos acadêmicos; d) docência em cursos de especialização; e e) aprovação em seleção para Programa de Pós-Graduação stricto sensu.

Santos, C. (2015) fez recomendações aos coordenadores pedagógicos enquanto formadores de professores, no âmbito do PNAIC, tais como construir uma formação dentro da escola, com o objetivo de envolver todos os profissionais que nela atuam, na partilha de experiências e na aquisição de conhecimentos. 
Couto e Gonçalves (2016) relatam as dificuldades encontradas pelos orientadores de estudo para colocar o PNAIC em ação nos municípios, tais como: a) criar a identidade do Programa como local, pois é considerado por muitos como mais um programa do Governo Federal; b) disponibilizar um espaço físico adequado para a realização das formações; e c) reproduzir o material do PNAIC para os encontros. Moreira e Silva (2016) afirmam que um desafio é manter a formação continuada no âmbito da universidade, como um processo permanente de formação em rede.

\section{Análise de material do PNAIC}

Esta categoria é composta por sete textos, que fazem a análise de materiais do PNAIC, sendo: Cadernos de Formação de Língua Portuguesa (seis textos) e Jogos de Alfabetização (um texto) ${ }^{5}$. A análise dos Cadernos de Língua Portuguesa destaca as concepções de alfabetização (MELO, 2015), de linguagem e de alfabetização (RESENDE, 2015), de oralidade (SOUZA, J., 2015); de formação, ensino e aprendizagem (SOUZA, 2014), de infância e lúdico (MONTEIRO, 2015), que se encontram explícitas ou não nos cadernos. Resende (2015) aponta que as concepções de linguagem e alfabetização defendem o processo de aprendizagem como reconstrução do sistema de escrita alfabética (SEA), a partir da ênfase na consciência fonológica. Com isso, ocorre um apagamento da linguagem como processo dialógico e dinâmico. Sobre as representações dos professores, contidas nos cadernos supracitados, Klein (2015) afirma que são recorrentes as representações dos docentes como reflexivos, mediadores, potencializadores e responsáveis.

Sobre as perspectivas teóricas presentes nos cadernos de formação do PNAIC, Souza (2014) identifica o construtivismo e o sociointeracionismo. Souza, J. (2015) afirma que os cadernos são pautados na concepção sociointeracionista de ensino, que contemplam características gerais do ensino da oralidade e que a leitura ainda prevalece nas atividades de formação dos professores. Melo (2015) afirma que há uma aglutinação de diferentes perspectivas teóricas (método fônico, letramento, construtivismo e sociointeracionismo).

Báfica et al. (2014) destacam que, no geral, os jogos ajudam o professor na prática pedagógica, e, os alunos no processo de aprendizagem. No entanto, apresentam limites: a) no que se refere à legibilidade gráfica (textual e imagética), pois alguns

\footnotetext{
5 Os textos abordam os Cadernos de Formação de Língua Portuguesa. No levantamento realizado, foram localizados trabalhos sobre os Cadernos de Formação de Matemática. No entanto, estes não foram incluídos nesta revisão pelo fato de que foram classificados como relatos de experiências, categoria que não foi contemplada nesta revisão. Ferreira e Fonseca (2017) apresentam uma análise dos Cadernos de Alfabetização Matemática do PNAIC.
} 
jogos apresentam imagens que não estão coerentes com o que representam; b) não possibilitam o desenvolvimento da leitura como compreensão; c) apresentam condições para o desenvolvimento da leitura de lista de palavras e desenvolvimento da consciência fonológica, mas não auxiliam a compreensão global de textos; e d) as regras dos jogos não são de fácil compreensão, dificultando a sua utilização sem a mediação do professor. Assim, os jogos não devem ser os únicos materiais disponíveis nas salas de aula.

\section{PNAIC e avaliação}

Nesta categoria, os textos apresentam análises sobre implementação da Avaliação Nacional da Alfabetização (ANA) ${ }^{6}$ no contexto do PNAIC (DICKEL, 2016; MICARELLO, 2015), bem como a avaliação e formação dos professores atreladas aos resultados das avaliações em larga escala (MINATEL et al., 2015; ROSA, 2014). Com relação à avaliação de professores, Minatel et al. (2015) abordam que, enquanto a prova para ingresso na carreira docente não acontece, a avaliação dos docentes, bem como de gestores e redes de ensino, efetiva-se de forma indireta, por meio da divulgação dos resultados de avaliações em larga escala.

Para Micarello (2015), o PNAIC configura-se como política nacional e, devido ao seu alcance e impacto, é importante ir além das práticas de avaliação propostas aos professores alfabetizadores, incluindo como a política é avaliada e qual seu alcance. Por isso, a autora aborda sobre a avaliação interna (realizada pelos professores com seus alunos) e a avaliação externa (ANA). A ideia de avaliação presente nos cadernos do PNAIC é de uma avaliação processual, que ocorre durante todas as etapas da alfabetização. Uma avaliação assim contribui para que se definam quais seriam as intervenções necessárias para o atendimento aos alunos, considerando seus ritmos de aprendizagem.

Para Silva (2015), há uma tensão entre reter ou promover o aluno no ciclo de alfabetização. Embora a formação do PNAIC tenha exercido um papel fundamental sobre a perspectiva de retenção escolar, algumas professoras ainda não concordam com a progressão continuada como processo pertinente à consolidação dos direitos de aprendizagem.

\footnotetext{
${ }^{6}$ A ANA tem por objetivo realizar um diagnóstico de alfabetização e letramento em Língua Portuguesa e alfabetização em Matemática, ao final do Ciclo de Alfabetização ( $3^{\circ}$ ano do Ensino Fundamental). Segundo dados do Ministério da Educação/Instituto Nacional de Estudos e Pesquisas Educacionais Anísio Teixeira (MEC/Inep), em 2016, os testes da ANA foram aplicados para 2,5 milhões de estudantes, de 50 mil escolas e 100 mil turmas.
} 


\section{PNAIC e currículo}

Essa categoria inclui cinco textos que abrangem discussões sobre o currículo no PNAIC.Axer (2014) destaca que o PNAIC apresenta a ideia de alfabetização e leitura que pretende desenvolver em todo o país, por meio de direitos de aprendizagem. Frangella (2016a;b) mostra que os direitos de aprendizagem são como eixos dos quais se desdobram os objetivos a serem alcançados pelos professores.

Toti (2014) analisou o currículo de Ciências Naturais do município de Jataí/GO e concluiu que o documento tinha como base, até 2013, o documento curricular oficial da Secretaria Estadual de Educação de Goiás que, por sua vez, tinha como base os Parâmetros Curriculares Nacionais (PCN). O documento foi reformulado em 2014, devido ao PNAIC. No entanto, o Programa não teve influência significativa na elaboração do currículo da disciplina de Ciências Naturais.

Leal (2015) analisou aproximações e distanciamentos entre as tendências presentes em 26 propostas curriculares brasileiras (sendo 12 documentos municipais e 14 documentos estaduais) e as orientações presentes nos materiais de formação de Língua Portuguesa do PNAIC. A primeira aproximação encontrada pela autora foi que, em ambos os documentos, a alfabetização é concebida na perspectiva de letramento, como um processo, no qual as crianças aprendem o funcionamento do SEA, de modo articulado aos usos sociais da escrita e da oralidade. Outro aspecto de aproximação é, com relação ao eixo de produção de textos, bastante valorizado nos documentos curriculares, assim como nos documentos curriculares, a defesa é, por atividades de produção de textos inserida em situações de usos sociais da escrita. No que se refere ao eixo de leitura, as orientações sobre a necessidade de se diversificar em materiais de leitura e o estabelecimento de finalidades para essas leituras foram contemplados, tanto nos documentos curriculares quanto nos cadernos do PNAIC.

Quanto aos distanciamentos, os documentos curriculares não contemplam os projetos didáticos e sequências didáticas de reflexões sobre os contextos de escrita que são apresentados nos cadernos do PNAIC. Outro distanciamento entre os documentos é que não há, nos cadernos do PNAIC, recomendações sobre as prescrições gramaticais que estão presentes nos documentos curriculares. Com relação ao tratamento/ampliação das temáticas tratadas nos textos, as diferenças entre os documentos referem-se, principalmente, à relevância dos assuntos selecionados para as atividades escolares, e à necessidade de abordar a leitura como algo essencial para a compreensão da realidade. Outra diferença exposta é que, nos cadernos do PNAIC, há mais discussões defendendo que a alfabetização seja um processo, no qual as crianças 
aprendam a ler, a escrever, a falar, a escutar, mas que, ao mesmo tempo, se apropriem da leitura, da escrita, da fala, da escuta e dos conhecimentos necessários para a vida, o que não aparece nos documentos curriculares de municípios e estados (LEAL, 2015).

\section{PNAIC e planejamento}

Os três textos incluídos nessa categoria abordam o planejamento como ferramenta essencial para o exercício da prática do professor. Na tomada de decisão sobre quais conteúdos e atividades deverá realizar com seus alunos, o professor contempla elementos que ajudam as crianças a avançarem na alfabetização (ELEUTÉRIO, 2014; JÄGER; PEREIRA; NÖRNBERG, 2014). Para Eleutério (2014), a proposta é que o planejamento assuma a função de mediador e articulador do trabalho coletivo, enquanto para Jäger, Pereira e Nörnberg (2014) ainda se faz necessário ampliar a dimensão conceitual sobre os princípios que devem orientar o processo de planejamento no ciclo de alfabetização.

Segundo Alcover (2016), as professoras que participaram de sua pesquisa trabalharam e desenvolveram as atividades propostas pelo PNAIC. Embora o planejamento e a realização das atividades tenham sido concebidos e executados de formas diversas, a autora percebeu que há um movimento de mudança na prática pedagógica das professoras.

\section{Ensino e aprendizagem no PNAIC}

O trabalho, incluído na categoria de ensino e aprendizagem, apresenta a prática pedagógica como palavra-chave, e envolve observações em uma sala de aula (classe multisseriada), além de entrevista com a professora (SÁ; PESSOA, 2016). As observações revelaram que a partir da participação da professora pesquisada no processo de formação continuada do PNAIC, sua prática pedagógica alterou-se nos seguintes aspectos: a) o trabalho com os livros de literatura abordou outros componentes curriculares, além da Língua Portuguesa; b) o trabalho com sequências didáticas tornou-se mais frequente na sala de aula; c) os projetos favoreceram a interdisciplinaridade; d) as atividades tornaram-se diversas, conforme o nível de leitura e escrita das crianças, e não de acordo com a faixa etária (como a professora organizava as atividades antes do PNAIC); e e) o uso de jogos foi ampliado. Entre os saberes apropriados pela professora, os que mais se destacaram foram: a prática sistemática do SEA, com a realização diária de atividades voltadas à sua apropriação, e a organização do tempo pedagógico, o qual favorecia o envolvimento das crianças em atividades diferenciadas. 


\section{Considerações finais}

De modo geral, os textos analisados podem ser sintetizados nos seguintes pontos:

- as pesquisas tendem a descrever o Programa e a analisar documentos, cadernos de formação e a opinião de orientadores de estudo e professores. Observou-se que são raras as pesquisas que incluem a observação do contexto da prática (salas de aula);

- as questões relacionadas ao PNAIC, como uma política educacional é problematizada em poucos trabalhos. A partir de uma análise política, pode-se argumentar que o PNAIC se propõe a resolver um problema da educação brasileira: as dificuldades para alfabetizar todos alunos dos anos iniciais do Ensino Fundamental. No entanto, apesar dos pontos positivos dessa política, uma de suas principais limitações é enfatizar mais o polo da formação continuada de professores. Uma alteração mais efetiva demanda investimentos em diversos aspectos, tanto intra quanto extraescolares;

- apenas algumas pesquisas levam em conta os antecedentes históricos do PNAIC e suas vinculações com as propostas do Movimento Todos pela Educação e mesmo com projetos similares implantados no Brasil (como é o caso do Programa Alfabetização na Idade Certa - PAIC, do estado do Ceará).

A partir dessa síntese, destacamos que há ainda diversos aspectos a serem aprofundados sobre o PNAIC, tais como:

- a realização de pesquisas que envolvam a análise dos níveis macro (produção da política), meso e micro (espaços de recontextualização da política);

- a análise das consequências/efeitos do PNAIC, em relação ao trabalho docente na sala de aula, bem como a identidade dos professores alfabetizadores;

- aprofundamento das noções de "pacto", "idade certa" e "direitos de aprendizagem" presentes no discurso e nos textos da política; e

- análise das relações do PNAIC com os modelos que enfatizam o desempenho e a política de resultados (melhoria de índices de desempenho x melhoria efetiva na aprendizagem para todos os alunos). 


\title{
The National Pact for Literacy at the Right Age in action: literature review
}

\begin{abstract}
This paper presents a literature review of the Pacto Nacional pela Alfabetização na Idade Certa (PNAIC) - National Pact for Literacy at the Right Age, covering 64 works, from 2013 to 2016. Research analyzed indicated the PNAIC as a comprehensive policy that combines several actions, including continuous teachers 'training. It concludes that there is a lack of research on the PNAIC in the classroom context and that few papers discuss the PNAIC as an education policy. Some aspects that still need to be deepened in future research are presented.
\end{abstract}

Keywords: PNAIC. Education policy. Continuous teacher training.

\section{El Pacto Nacional por la Alfabetización en la Edad Cierta en acción: revisión de la literatura}

\section{Resumen}

El articulo presenta una revisión de literatura sobre el Pacto Nacional por la Alfabetización en la Edad Cierta (PNAIC), abarcando 64 trabajos, del periodo de 2013 a 2016. Las investigaciones apuntaron al PNAIC como una politica integral que conjuga diversas acciones, entre ellas, la formación continuada de profesores alfabetizadores. Se concluyó que hay ausencia de investigaciones sobre el PNAIC en el contexto del aula y pocos trabajos discuten las cuestiones del PNAIC como politica educativa. Se presentan algunos aspectos que aún necesitan ser profundizados en investigaciones futuras.

Palabras clave: PNAIC. Política Educativa. Formación continuada de maestros. 


\section{Referências}

ALCOVER, K. C. PNAIC e a prática pedagógica de algumas professoras da rede municipal de educação de Primavera do Leste - MT. Professare, v. 5, n. 3, p. 23-50, 2016.

ALFERES, M. A. Pacto Nacional pela Alfabetização na Idade Certa: uma análise contextual da produção da política e dos processos de recontextualização. 2017. 246 f. Tese (Doutorado em Educação) Universidade Estadual de Ponta Grossa, Ponta Grossa, 2017.

ALFERES, M. A.; MAINARDES, J. A recontextualização do Pacto Nacional pela Alfabetização na idade certa - PNAIC: uma análise dos contextos macro, meso e micro. Currículo Sem Fronteiras, v. 18, n. 2, p. 1-28, maio/ago. 2018.

ALMEIDA, M. E. V. As vozes que emergem do pacto federativo: o pacto nacional pela alfabetização na idade certa (PNAIC) em foco e suas implicações na cidade do Rio de Janeiro. 2014. 126f. Dissertação (Mestrado em Educação)

— Universidade Federal do Rio de Janeiro, Rio de Janeiro, 2014.

ANSILIERO, J. B.; ROSA, Z. R. F. Alfabetização e letramento: percorrendo o caminho até o Pacto Nacional da Alfabetização na Idade Certa. Unoesc \& Ciência, v. 5, n. 2, p. 191-202, jun./dez. 2014.

ANTUNES, A. A.; MARQUES, M. R.; VARGAS, S. L. Pacto Nacional pela Alfabetização na Idade Certa: a importância da leitura deleite na formação do professor leitor. Linha Mestra, v. 8, n. 24, p. 217-20, jan./jul. 2014.

ANTUNES, H. S.; RECH, A. J. D.; ÁVILA, C. C. Educação inclusiva e formação de professores: desafios e perspectivas a partir do Pacto Nacional pela Alfabetização na Idade Certa. Práxis Educativa, v. 11, n. 1, p. 171-98, jan./abr. 2016. https://doi.org/10.5212/PraxEduc.v.11i1.0008

AXER, B. Diálogos entre currículo e leitura: o caso do PNAIC. Linha Mestra, v. 8 , n. 24 , p. 626-9, jan./jul. 2014.

BÁFICA, A. P. S.; BARROS, J. A.; COUTO, M. E. S. A aquisição da leitura: uma análise dos jogos didáticos disponibilizados pelo Pacto Nacional pela Alfabetização na Idade Certa - PNAIC. Linha Mestra, v. 8, n. 24, p. 425-9, jan./jul.2014.

BALL, S. J. The education debate. Bristol: Policy Press, 2013.

BALL, S. J.; MAGUIRE, M.; BRAUN, A. Como as escolas fazem as políticas: atuação em escolas secundárias. Ponta Grossa: UEPG, 2016. 
BARROS, L. S.; PEREIRA, U. C. Pacto Nacional pela Alfabetização na Idade Certa: contribuições para a formação de leitores. Linha Mestra, v. 8, n. 24, p. 1943-6, jan./jul. 2014.

BOSCOLO, E. A. B.; CAMPOS, P. R. I. Rios e margens na formação de professores alfabetizadores: da política pública para o cotidiano da sala de aula. Linha Mestra, v. 8, n. 24, p. 1091-1094, jan./jul. 2014.

BRASIL. Portaria No 867, de 4 de julho de 2012. Institui o Pacto Nacional pela Alfabetização na Idade Certa e as ações do Pacto e define suas diretrizes gerais. Diário Oficial da União, 5 jul. 2012.

BRITO, V. M.; VIÉDES, S. C. A. A política educacional de alfabetização da criança consubstanciada pelos programas, projetos e pactos: o novo ou tudo de novo? Revista HISTEDBR On-line, v. 15, n. 63, p. 147-71, jun. 2015. https:// doi.org/10.20396/rho.v15i63.8641176

CABRAL, G. R. Pensando a inserção de políticas públicas de formação continuada de professoras alfabetizadoras em um município de pequeno porte: o que dizem os sujeitos dessa formação? 2015. 302 f. Tese (Doutorado em Educação) — Pontifícia Universidade Católica do Rio de Janeiro, Rio de Janeiro, 2015.

CARDOSO, C. J.; CARDOSO, A. L. J. Formação continuada no contexto do Pacto Nacional pela Alfabetização na Idade Certa: alinhamento entre práticas, princípios formativos e objetivos. Práxis Educativa, v. 11, n. 1, p. 89-106, jan./abr. 2016.

CARDOSO, C. J.; RODRIGUES, S. F. P. Pacto Nacional pela Alfabetização na Idade Certa em Mato Grosso: desafios e resultados. Linha Mestra, v. 8, n. 24, p. 652-6, jan./jul. 2014.

COUTO, M. E. S.; GONÇALVES, A. L. A formação dos formadores: um estudo sobre o PNAIC. Práxis Educativa, v. 11, n. 1, p. 151-70, jan./abr. 2016.

CRUZ, M. M. P.; MARTINIAK, V. L. Pacto Nacional pela Alfabetização na Idade Certa: limites e possibilidades. In: MARTINIAK, V. L. (Org.). Formação de professores alfabetizadores: políticas e práticas. Ponta Grossa: Estúdio Texto, 2015. p. 35-55.

DICKEL, A. A Avaliação Nacional da Alfabetização no contexto do Sistema de avaliação da educação Básica e do Pacto Nacional pela Alfabetização na Idade Certa: responsabilização e controle. Cadernos Cedes, v. 36, n. 99, p. 193-206, maio/ago. 2016. 
ELEUTÉRIO, P. F. S. Pacto Nacional pela Alfabetização na Idade Certa no RN: a repercussão da formação docente sobre o planejamento do professor alfabetizador no processo de ensino e aprendizagem no espaço escolar. Linha Mestra, v. 8, n. 24, p. 2751-4, jan./jul. 2014.

FERREIRA, P. F.; FONSECA, M. S. A cultura da performatividade na organização do trabalho pedagógico: a formação matemática nos cadernos do Pacto Nacional pela Alfabetização na Idade Certa (Pnaic). Ensaio: Avaliação e Políticas Públicas em Educação, , v. 25, n. 97, p. 809-30, out./dez. 2017. https://doi.org/10.1590/s0104-40362017002500901

FIDELIS, A. C. S.; GUEDES-PINTO, A. L.; TONIN, F. B. Práticas de leitura deleite no processo de alfabetização: diálogos com a proposta de formação do Pacto/UNICAMP. Linha Mestra, v. 8, n. 24, p. 361-364, jan./jul. 2014.

FRAMBACH, F. A.; VIDAL, A. F. A formação continuada do PNAIC: entre diálogos e experiências de (de/trans)formação. In: CONSTANT, E.; NASER, L.; SANTOS, W. S. (Orgs.). Educação em movimento: artigos e relatos de experiências do Pacto Nacional para a Alfabetização na Idade Certa no Rio de Janeiro em 2014. Belo Horizonte: Rona, 2015. p. 40-55.

FRANGELLA, R. C. P. Políticas de formação do alfabetizador e produção de políticas curriculares: pactuando sentidos para formação, alfabetização e currículo. Práxis Educativa, v. 11, n. 1, p. 107-128, jan./abr. 2016 a.

Um pacto curricular: o Pacto Nacional pela Alfabetização na Idade Certa e o desenho de uma Base Comum Nacional. Educação em Revista, v. 32, n. 2, p. 69-89, abr./jun. 2016b.

GARCEZ, W. R. Questões relacionadas à necessidade de formação continuada do professor de matemática dos anos iniciais. In:

CONSTANT, E.; NASER, L.; SANTOS, W. S. (Orgs.). Educação em movimento: artigos e relatos de experiências do Pacto Nacional para a Alfabetização na Idade Certa no Rio de Janeiro em 2014. Belo Horizonte: Rona, 2015. p. 98-121.

JÄGER, J. J.; PEREIRA, V. B.; NÖRNBERG, M. Escritas de professoras orientadoras de estudo do PNAIC-MEC sobre planejamento. In: COLÓQUIO NACIONAL: DIÁLOGOS ENTRE LINGUAGEM E EDUCAÇÃO, 2; ENCONTRO DO NEL E II SEMINÁRIO DO PIBID DE LETRAS DA FURB, 9, Blumenau, 2014. Anais... Blumenau: FURB, 2014. p. 1-15. 
JESUS, F. S. Propostas filosóficas para os cursos de formação de professores: algumas considerações sobre o Pacto Nacional pela Alfabetização na Idade Certa PNAIC. In: CONSTANT, E.; NASER, L.; SANTOS, W. S. (Orgs.). Educação em movimento: artigos e relatos de experiências do Pacto Nacional para a Alfabetização na Idade Certa no Rio de Janeiro em 2014. Belo Horizonte: Rona, 2015. p. 84-97.

KAIUCA, M. A. Interfaces e diálogos do PNAIC numa perspectiva interdisciplinar. In: CONSTANT, E.; NASER, L.; SANTOS, W. S. (Orgs.). Educação em movimento: artigos e relatos de experiências do Pacto Nacional para a Alfabetização na Idade Certa no Rio de Janeiro em 2014. Belo Horizonte: Rona, 2015. p. 56-69.

KLEIN, A. M.; GALINDO, M. A.; D’AGUA, S. V. N. L. Os significados da formação docente desenvolvida pelo Pacto Nacional pela Alfabetização na Idade Certa. Práxis Educativa, v. 11, n. 1, p. 129-50, jan./abr. 2016.

KLEIN, J. M. Representações e identidades docentes nos cadernos de formação do programa Pacto Nacional pela Alfabetização na Idade Certa (PNAIC). 2015. 138 f. Dissertação (Mestrado em Educação) — Universidade Luterana do Brasil, Canoas, 2015.

LEAL, T. F. Currículo no Pacto Nacional pela Alfabetização na Idade Certa: os direitos de aprendizagem em discussão. Educação em Foco, ed. esp., p. 23-44, fev. 2015.

LEITE, E. A. S. Alfabetização e letramento: desafios e possibilidades de uma escola pública municipal a partir do Pacto Nacional pela Alfabetização na Idade Certa. 2014. 140 f. Dissertação (Mestrado Profissional em Gestão e Avaliação da Educação Pública) — Universidade Federal de Juiz de Fora, Juiz de Fora, 2014.

\section{LUCACHINSKI, E. S. Pacto Nacional pela Alfabetização na Idade}

Certa: a formação de professores para a prática alfabetizadora com alunos com deficiência. 2015. 185 f. Dissertação (Mestrado em Educação) Universidade Comunitária da Região de Chapecó, Chapecó, 2015.

LUCACHINSKI, E. S.; TONDIN, C. F. Alfabetização de crianças com deficiência e redução das desigualdades no âmbito do Pacto Nacional pela Alfabetização na Idade Certa. Revista da FAEEBA - Educação e Contemporaneidade, v. 25, n. 45, p. 217 34, jan./abr. 2016. https://doi.org/10.21879/faeeba2358-0194.2016.v25.n45.p\%25p

MANZANO, T. S. Formação continuada de professores alfabetizadores do Pacto Nacional pela Alfabetização na Idade Certa PNAIC no Município de São Paulo: proposições e ações. 2014. 127 f. Dissertação (Mestrado em Educação: História, Política e Sociedade) — Pontifícia Universidade Católica de São Paulo, São Paulo, 2014. 
MARTINIAK, V. L.; CRUZ, M. M. P. A formação continuada de professores alfabetizadores: desafios e perspectivas. In: MARTINIAK, V. L. (Org.). Formação de professores alfabetizadores: políticas e práticas. Ponta Grossa: Estúdio Texto, 2015. p. 13-34.

MELO, E. P. C. B. N. PNAIC: uma análise crítica das concepções de alfabetização presentes nos cadernos de formação docente. 2015. 252 f. Dissertação (Mestrado em Educação) — Universidade Federal de São Carlos, Sorocaba, 2015.

MICARELLO, H. A. L. S. A avaliação no âmbito do Pacto Nacional pela Alfabetização na Idade Certa. Educação em Foco, ed. esp., p. 63-79, fev. 2015. https://doi.org/10.22195/2447-5246v0n020152957

MINATEL, M. Q. P.; SANTOS, S. M. C.; GUIMARÃES, S. R. K. Avaliação dos professores no Pacto Nacional pela Alfabetização na Idade Certa (PNAIC). Revista Diálogo Educacional, v. 15, n. 44, p. 157-72, jan./abr. 2015. https://doi.org/10.7213/dialogo.educ.15.044.DS07

MINDIATE, M. J. Uma compreensão da alfabetização matemática como política pública no Pacto Nacional pela Alfabetização na Idade Certa. 2015. 86 f. Dissertação (Mestrado em Educação em Ciências e em Matemática) Universidade Federal do Paraná, Curitiba, 2015.

MONTEIRO, A. B. B. As concepções de lúdico a partir da unidade quatro dos cadernos de formação do Pacto Nacional pela Alfabetização na Idade Certa - PNAIC - 2013. 2015. 132 f. Dissertação (Mestrado em Educação) Fundação Universidade do Rio Grande, Rio Grande, 2015.

MOREIRA, J. A. S.; SAITO, H. I. Da erradicação do analfabetismo ao compromisso de alfabetizar na idade certa: rumo a uma política nacional para alfabetização escolar? Teoria e Prática da Educação, v. 16, n. 3, p. 55-64, set./ dez. 2013.

MOREIRA, J. A. S.; SILVA, R. V. Políticas para a formação de professores e as recomendações do Banco Mundial: interfaces com o contexto atual da formação de professores alfabetizadores no Brasil. Práxis Educativa, v. 11, n. 1, p. 37-61, jan./abr. 2016. https://doi.org/10.5212/PraxEduc.v.11i1.0002

PIRES, A. P.; SCHNECKENBERG, M. Política de formação continuada de professores: o PNAIC e o desafio da alfabetização na idade certa. Revista CAMINE: Caminhos da Educação, v. 7, n. 2, p. 103-26, 2015. 
PORTO, Z. G. Pacto Nacional pela Alfabetização na Idade Certa: concepções, desafios, perspectivas. In: ALMEIDA, L. C.; LAPLANE, A. L. F.; PAIXÃO, A. H. (Orgs.). Mudanças atuais na sociedade brasileira e o Sistema Nacional de Educação: qualidade da educação pública como direito humano. Campinas: FE/UNICAMP, 2016. p. 64-89.

RESENDE, V. A. D. L. Análises dos pressupostos de linguagem nos cadernos de formação em Língua Portuguesa do Pacto Nacional pela Alfabetização na Idade Certa - PNAIC. 2015. 215 f. Tese (Doutorado em Educação) — Faculdade de Filosofia e Ciências, Univesidade Estadual Paulista, Marília, 2015.

RIBEIRO, S.; ALBUQUERQUE, A. S. Educação do campo e o (im)Pacto Nacional da Alfabetização na Idade Certa (PNAIC). Educação em Foco, ed. esp., p. 45-61, fev. 2015. https://doi.org/10.22195/2447-5246v0n020152956

ROSA, K. S. Pacto Nacional de Alfabetização na Idade Certa: repercussões da Provinha Brasil. 2014. 106 f. Dissertação (Mestrado em Educação) Universidade Regional Integrada do Alto Uruguai e das Missões, Frederico Westphalen, RS, 2014.

SÁ, C. F.; PESSOA, A. C. R. G. Práticas de alfabetização em turma multisseriada no contexto do Pacto Nacional pela Alfabetização na Idade Certa (PNAIC). Práxis Educativa, v.11, n. 1, p. 215-41, jan./abr. 2016. https://doi. org/10.5212/PraxEduc.v.11i1.0010

SALOMÃO, R. A formação continuada de professores alfabetizadores: do Pró-Letramento ao PNAIC. 2014. 117 f. Dissertação (Mestrado em Educação) —Universidade Estadual de Ponta Grossa, Ponta Grossa, PR, 2014.

SANTIAGO, L. T. M. As influências do PNAIC na dinâmica do processo de alfabetização. 2015. 143 f. Dissertação (Mestrado em Educação) - Centro Universitário La Salle, Canoas, 2015.

SANTOS, C. A. O papel do coordenador pedagógico no processo formativo dos professores do ciclo de alfabetização: o Pacto Nacional pela Alfabetização na Idade Certa - PNAIC. 2015. 94 f. Dissertação (Mestrado Profissional em Educação: formação de formadores) - Pontifícia Universidade Católica de São Paulo, São Paulo, 2015.

SANTOS, N. F. C. Entre o proposto e o almejado: da proposta do Pacto Nacional pela Alfabetização na Idade Certa às expectativas almejadas por docentes participantes. 2015. 123 f. Dissertação (Mestrado em Educação) Universidade Nove de Julho, São Paulo, 2015. 
SANTOS, P. R. A. Pacto Nacional pela Alfabetização na Idade Certa (PNAIC-2012): análise e perspectiva de ação. 2015. 73 f. Dissertação (Mestrado em Educação) — Universidade do Oeste Paulista, Presidente Prudente, 2015.

SHIMAZAKI, E. M.; MENEGASSI, R. J. O formador de professores de Língua Portuguesa do PNAIC e as alterações em suas práticas profissionais. Práxis Educativa, v. 11, n. 1, p. 199-213, jan./abr. 2016. https://doi. org/10.5212/PraxEduc.v.11i1.0009

SILVA, L. D. S. A tensão entre as perspectivas da retenção escolar e a instituição da progressão continuada no contexto de prática do PNAIC. 2015. 191 f. Dissertação (Mestrado em Educação) — Universidade Federal da Paraíba, João Pessoa, 2015.

SILVA, M. A.; OLIVEIRA, M. A.; CAETANO, M. R. O Programa Nacional da Alfabetização na Idade Certa (PNAIC) no Vale do Paranhana: o contexto da prática. COLÓQUIO - Revista do Desenvolvimento Regional - Faccat, v. 11, n. 2, p.45-53, jul./dez. 2014. https://doi.org/10.26767/coloquio.v11i2.151

SILVA, R. R. D.; CARVALHO, R. S.; SILVA, R. M. D. Políticas contemporâneas de formação de alfabetizadores no Brasil: entre a potencialização dos desempenhos e a gestão pedagógica das inovações. Práxis Educativa, v. 11, n. 1, p. 15-35, jan./abr. 2016. https://doi.org/10.5212/PraxEduc.v.11i1.0001

SOUZA, E. C. P.; COSTA, D. Q. S. Fóruns das Universidades: a construção de elos na formação continuada de professores do PNAIC. In: CONSTANT, E.; NASER, L.; SANTOS, W. S. (Orgs.). Educação em movimento: artigos e relatos de experiências do Pacto Nacional para a Alfabetização na Idade Certa no Rio de Janeiro em 2014. Belo Horizonte: Rona, 2015. p. 16-28.

SOUZA, E. E. P. A formação continuada do professor alfabetizador nos cadernos do Pacto Nacional pela Alfabetização na Idade Certa (PNAIC). 2014. 358f. Dissertação (Mestrado em Educação) - Universidade Federal de Santa Catarina, Florianópolis, 2014.

SOUZA, J. T. Concepção de oralidade presente no PNAIC e na formação dos orientadores de estudos e professores alfabetizadores de Pernambuco. 2015. 226 f. Dissertação (Mestrado em Educação) — Universidade Federal de Pernambuco, Recife, 2015.

SOUZA, T. P. O trabalho docente e os programas de formação continuada para professores alfabetizadores. 2015105 f. Dissertação (Mestrado em Educação) - Universidade Metodista de Piracicaba, 2015. 
TEDESCO, S. Formação continuada de professores: experiências integradoras de políticas educacionais - PNAIC e PROUCA - para alfabetização no Ensino Fundamental de uma escola pública. 2015. 91f. Dissertação (Mestrado em Educação) — Faculdade de Educação, Pontifícia Universidade Católica do Rio Grande do Sul, Porto Alegre, 2015.

TODOS PELA EDUCAÇÃO. Compromisso Todos pela Educação: Todos pela Educação rumo a 2022. São Paulo, 2006.

TOTI, M. C. S. O currículo de ciências no ciclo de alfabetização e o efeito do Pacto Nacional pela Alfabetização na Idade Certa (PNAIC): um estudo sobre um município do sudoeste goiano Jataí. 2014. 181 f. Dissertação (Mestrado Profissional em Educação para Ciências e Matemática) - Instituto Federal de Educação, Ciência e Tecnologia de Goiás, Jataí, 2014.

VENTURA, A. L. S. L. PNAIC Polo São Paulo: desafios da implementação de uma Política Pública de Educação. 2016. 104 f. Dissertação (Mestrado em Educação) — Universidade Cidade de São Paulo, São Paulo, 2016.

VIÉDES, S. C. A. Políticas públicas em alfabetização: o Pacto Nacional pela Alfabetização na Idade Certa no município de Anastácio - MS. 2015. 148 f. Dissertação (Mestrado Profissional em Educação) — Universidade Estadual de Mato Grosso do Sul, Campo Grande, 2015.

VIEIRA, C. F. D. Formação continuada de professores no Pacto Nacional pela Alfabetização na Idade Certa - PNAIC: do texto ao contexto. 2015. 156 f. Dissertação (Mestrado em Educação) - Universidade Federal do Piauí, Teresina, 2015.

\section{Informações dos autores}

Marcia Aparecida Alferes: Secretaria de Estado da Educação do Paraná. Mestre em Educação pela Universidade Estadual de Ponta Grossa e Doutora em Educação na Universidade Estadual de Ponta Grossa na linha de pesquisa "História e Política Educacionais”. Contato: profsecr@yahoo.com.br

Jefferson Mainardes: Professor Associado do Departamento de Educação da Universidade Estadual de Ponta Grossa e do Programa de Pós-Graduação em Educação (Mestrado e Doutorado). Desde de agosto de 2015 é Honorary Senior Research Associate do UCL/ Institute of Education (Londres). Contato: jefferson.m@uol.com.br 